\title{
Area at End Ventricular Systole
}

National Cancer Institute

\section{Source}

National Cancer Institute. Area at End Ventricular Systole. NCI Thesaurus. Code C127538.

The 2-dimensional surface enclosed within a boundary and measured at end ventricular systole. 